\title{
Growth, magnetic properties and the effect of cobalt addition in metal-organic chemical vapour deposited (MOCVD) gamma iron oxide thin films for magnetic recording applications
}

\author{
SANDIP DHARA, A C RASTOGI and B K DAS \\ Materials Division, National Physical Laboratory, Dr K S Krishnan Marg, New Delhi \\ 110012 , India \\ MS received 15 November 1993; revised 13 May 1994
}

\begin{abstract}
The present study aims at investigating MOCVD technique for the deposition of magnetic oxide thin films using volatile metal-organic compounds as source material. A three-step scheme has been described to form $\gamma-\mathrm{Fe}_{2} \mathrm{O}_{3}$ phase starting from $\alpha-\mathrm{Fe}_{2} \mathrm{O}_{3}$ films as-deposited in optically heated atmospheric cold wall CVD reactor. Growth of $\gamma-\mathrm{Fe}_{2} \mathrm{O}_{3}$ in a two-step process has been performed by depositing $\mathrm{Fe}_{3} \mathrm{O}_{4}$ phase directly by resistively heated low-pressure CVD (LPCVD) technique. Role of substrate temperature in controlling the oxidation leading to direct formation of metastable $\gamma-\mathrm{Fe}_{2} \mathrm{O}_{3}$ phase (single-step scheme) by atmospheric CVD technique has been described. A new mode of introduction of cobalt in the film, namely heterogeneous dispersion of cobalt in the $y-\mathrm{Fe}_{2} \mathrm{O}_{3}$ matrix, has also been described. Crystallographic structure, microstructure and magnetic properties of the films have been studied in detail. Biaxial vector coil and high-temperature magnetic studies were carried out for determining the nature of anisotropy in the $\gamma-\mathrm{Fe}_{2} \mathrm{O}_{3}$ film. Growth of $\gamma-\mathrm{Fe}_{2} \mathrm{O}_{3}$ films in different schemes have been discussed from the studies of growth kinetics in a coldand hot-wall-type reactor chambers.
\end{abstract}

Keywords. MOCVD; LPCVD; $\gamma-\mathrm{Fe}_{2} \mathrm{O}_{3}$; cobalt-modified $\gamma-\mathrm{Fe}_{2} \mathrm{O}_{3}$ films; magnetocrystalline anisotropy; uniaxial anisotropy; coercivity.

\section{Introduction}

Ferrimagnetic oxides with their moderate values of coercivity and remanent magnetization are ideal as magnetic recording materials for fabrication of magnetic recording media. The demand for long-life, reliable and high-density recording media has led to extensive research both in materials development, mostly in the preparation of oxide (Kishimoto et al 1979) and metallic thin film media (Iwasaki et al 1979), and in the innovation of new recording techniques (Abe and Gomi 1990). Ferrimagnetic oxides are possible with different crystallographic structures, e.g. spinel structure with one or two metallic ions in a formula unit, hexagonal magneto-plumbite structure and garnet structure. Magnetite $\left(\mathrm{Fe}_{3} \mathrm{O}_{4}\right)$ and maghemite $\left(\gamma-\mathrm{Fe}_{2} \mathrm{O}_{3}\right)$ phases of iron oxide possess spinel structure and are commercially used as magnetic recording material (Hattori et al 1979). Particulate iron oxide is a widely used medium for the magnetic recording of both continuous audio signals and discrete digital signals in longitudinal mode of operation (Mee et al 1967). Thrust for higher density (Bate 1978) of data storage in case of digital recording has forced researchers to improve upon the magnetic properties, e.g. coercivity and remanent magnetization of the existing iron oxide media. Extensive studies have also been undertaken to develop new materials, viz. Co-modified iron oxides (Nakamura et al 1987) and hexagonal ferrites like barium ferrite (Kotnala 1992) with magneto-plumbite structure. However, in particulate media there are constraints on further improvement of the density of 
digital recording. As density of recording increases, volume of the recorded bit decreases. Small volume of the recorded bit leads to higher noise owing to statistical fluctuations of the number of magnetic particles in case of particulate media (Bate 1978). In high-density recording, as the recorded bits come close to each other, demagnetization field of two adjacent magnetized zones increases (Chantrell and O'Grady 1992). In order to remove the demagnetization effect magnetic particles with higher coercivity are required, which is difficult to obtain in case of micron-sized particles (Bate 1965). This led researchers to develop thin films of those materials with very fine grain size in order to improve the signal-to-noise ratio and coercivity of the recording media.

Maghemite phase of iron oxide $\left(\gamma-\mathrm{Fe}_{2} \mathrm{O}_{3}\right)$ is widely used for its superior recording characteristics and high mechanical strength (Inagaki et al 1976). $\gamma-\mathrm{Fe}_{2} \mathrm{O}_{3}$ is a metastable phase of iron oxide and is preferred over the $\mathrm{Fe}_{3} \mathrm{O}_{4}$ phase, as the latter has lower oxidation state. $\mathrm{Fe}^{2+}$ ions are oxidized gradually under atmospheric conditions causing distortion in recorded information (Meiklejohn 1986). $\gamma-\mathrm{Fe}_{2} \mathrm{O}_{3}$ films are prepared mostly in a three-step process where $\alpha-\mathrm{Fe}_{2} \mathrm{O}_{3}$ phase is deposited by different techniques (Dhara et al 1992a) as a first step. As-deposited films are reduced to $\mathrm{Fe}_{3} \mathrm{O}_{4}$ phase in a controlled $\mathrm{H}_{2}$ ambient at low temperature $\left(\leqslant 350^{\circ} \mathrm{C}\right)$ and finally these reduced films are annealed $\left(250-450^{\circ} \mathrm{C}\right)$ in oxygen and/or air ambient to form $\gamma-\mathrm{Fe}_{2} \mathrm{O}_{3}$ phase. A two-step process for the preparation of $\gamma-\mathrm{Fe}_{2} \mathrm{O}_{3}$ phase is also reported (Heller 1976), where $\mathrm{Fe}_{3} \mathrm{O}_{4}$ phase is deposited directly by reactive r.f. sputtering in a controlled $\mathrm{Ar} / \mathrm{O}_{2}$ ambient and the as-deposited films are oxidized to obtain $\gamma-\mathrm{Fe}_{2} \mathrm{O}_{3}$ phase. Direct deposition of $\gamma-\mathrm{Fe}_{2} \mathrm{O}_{3}$ phase is also successfully reported (Ohta and Terada 1986) by pulsed reactive r.f. sputtering of iron target.

Addition of cobalt in the formation of maghemite phase leads to the formation of Co-modified $\gamma-\mathrm{Fe}_{2} \mathrm{O}_{3}$ phase. $\mathrm{Co}^{2+}$ plays a crucial role in introducing anisotropy in the medium, which is likely to arise from the exchange coupling between $\mathrm{Co}^{2+}$ and $\mathrm{Fe}^{3+}$ ions as suggested first by Slonczewski (1958) and then later on by Tachiki (1960). Cobalt addition enhances anisotropy in the iron oxide media as seen from earlier reports (Nakamura et al 1987) where 0-6 at. wt.\% of cobalt was used for the formation of Co-modified $\gamma-\mathrm{Fe}_{2} \mathrm{O}_{3}$ phase. In particulate media, cobalt can be introduced using several processes such as by Co-doping (Koster 1972), by Co-adsorption (Imaoka et al 1978) and by epitaxial surface deposition of Co-ferrite (Kishimoto et al 1979). Location of $\mathrm{Co}^{2+}$ ions in the lattice of $\gamma-\mathrm{Fe}_{2} \mathrm{O}_{3}$ determines the nature of anisotropy introduced in the medium and the stability of the medium. Co-doped $\gamma-\mathrm{Fe}_{2} \mathrm{O}_{3}$ medium shows the presence of uniaxial anisotropy and magnetic instability in the medium (Hayama et al 1980). This instability in the medium is ascribed to the movement of $\mathrm{Co}^{2+}$ ions in the Co-doped medium. The strong temperature dependence of coercivity confirms the uniaxial nature of anisotropy present in the medium. On the other hand, Co-adsorbed and epitaxial surface deposited media show magnetocrystalline anisotropy and magnetic stability in the media. Coercivity in case of Co-adsorbed medium shows insignificant temperature dependence (Meng et al 1987).

Perhans the most basic change in the last fifteen years or so has been the use of continuous thin-film media of iron-based magnetic oxides instead of particulate media for the purpose of high-density digital recording and to increase signal-to-noise ratio at high density of recording. The most extensively used technique for processing these materials in thin-film form is reactive r.f. sputtering (Chen et al 1988) followed by post-deposition heat treatment. Alternative deposition techniques have, however, 
received little or no attention. Among these, chemical vapour deposition (CVD) offers several advantages like high deposition rate capability and novel process controls which would be useful in obtaining the desired composition and structure. So far these iron and iron oxide-based thin films have been deposited by CVD techniques involving deposition from pure iron source using $\mathrm{HCl}$ transport (Babkin et al 1984) and by MOCVD technique employing metal-organic complexes of iron acetyl acetonate as the source material (Dhara et al 1992a). Thus while only isolated studies on CVD technique have been done, practically no detailed studies have been reported on undoped and cobalt-doped iron oxide.

Keeping the above perspective, the present study aims at studying the MOCVD technique for the deposition of magnetic oxide thin films using volatile metal-organic compounds as source material. The growth techniques of magnetic iron oxide films in three different possible schemes are discussed. A three-step scheme to form $\gamma-\mathrm{Fe}_{2} \mathrm{O}_{3}$ phase starting from $\alpha-\mathrm{Fe}_{2} \mathrm{O}_{3}$ films as-deposited by optically heated atmospheric chemical vapour deposition in a cold-wall CVD reactor using metal-organic complexes of $\mathrm{Fe}^{3+}$ (MOCVD) has been described. Growth of $\gamma-\mathrm{Fe}_{2} \mathrm{O}_{3}$ in a two-step process has also been performed by depositing $\mathrm{Fe}_{3} \mathrm{O}_{4}$ phase directly by resistively heated low-pressure MOCVD reactor. Direct deposition of $\gamma-\mathrm{Fe}_{2} \mathrm{O}_{3}$ films in a single-step scheme by atmospheric MOCVD technique has been described.

\section{Experimental}

Iron oxide thin films were deposited on glass substrates (Corning \#7059) by CVD technique using ferric $\beta$-diketonates of acetyl acetonate or dipivalyolmethanate (DPM). Argon was used as the transporting gas. In the three-step and single-step schemes deposition was carried out in a cold-wall-type tubular optically heated atmospheric CVD reactor (figure 1). Substrates on graphite susceptor kept horizontal with respect to vapour direction were indirectly heated by tungsten halogen lamps. Precursors were evaporated by a secondary heater. Typical carrier gas flow rate was 1.51 per min. Cobalt was added to iron oxide films by coevaporating cobaltus acetyl acetonate with ferric acetyl acetonate, used in those two schemes. Ferric acetyl acetonate $\left[\mathrm{Fe}(\mathrm{acac})_{3}\right]$ and cobaltus acetyl acetonate $\left[\mathrm{Co}(\mathrm{acac})_{2}\right]$ complexes were synthesized by refluxing $\mathrm{FeCl}_{3}$ and $\mathrm{CoSO}_{4}$ with acetyl acetonate and controlling $\mathrm{pH}$

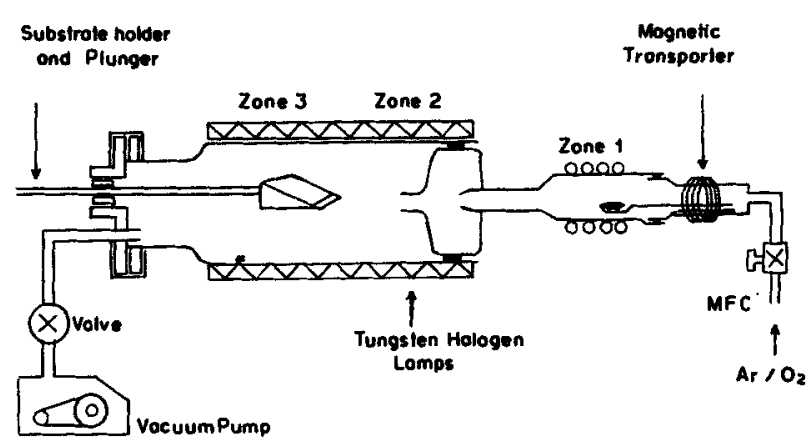

Figure 1. Schematic of optically heated CVD reactor. 


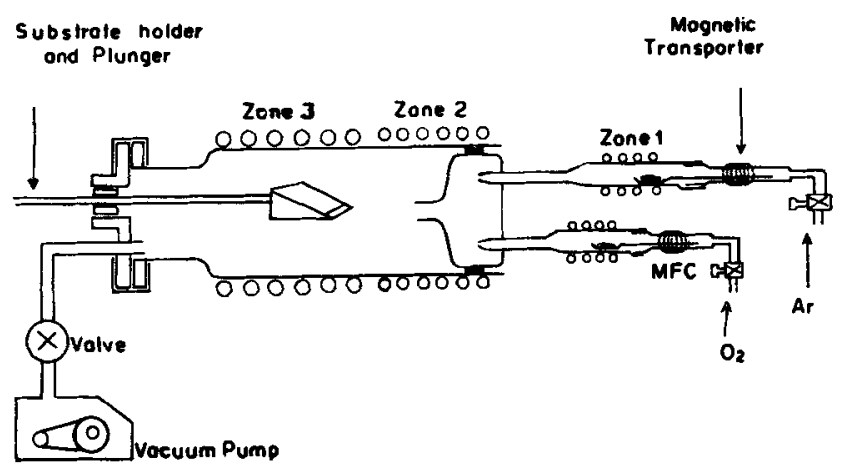

Figure 2. Schematic of resistively heated CVD reactor.

to 5-6 with subsequent purification process of recrystallization and sublimation.

$$
\begin{aligned}
& \mathrm{FeCl}_{3}+3 \mathrm{H}(\mathrm{acac})=\mathrm{Fe}(\mathrm{acac})_{3}+3 \mathrm{HCl}, \\
& \mathrm{CoSO}_{4}+2 \mathrm{H}(\mathrm{acac})=\mathrm{Co}(\mathrm{acac})_{2}+\mathrm{H}_{2} \mathrm{SO}_{4} .
\end{aligned}
$$

In the two-step scheme, deposition was performed in a hot-wall-type resistively heated low-pressure CVD (LPCVD) reactor chamber (figure 2). Substrates on steel susceptor inclined at $45^{\circ}$ with respect to vapour direction were heated resistively in a separate zone followed by a mixer zone where evaporant from resistively heated source heating zone was fed into. More than one evaporation chamber facilitate the growth of multicomponent films. In the present study we have used only one evaporation chamber for the growth of iron oxide films. Metal-organic DPM complex of iron $\left[\mathrm{Fe}(\mathrm{DPM})_{3}\right]$ was used as precursor. $\mathrm{Fe}(\mathrm{DPM})_{3}$ was prepared by using $\mathrm{FeCl}_{3}$ and HDPM in an alcoholic solution and purifying the precipitate by recrystallization and sublimation techniques.

$$
\mathrm{FeCl}_{3}+3 \mathrm{HDPM}=\mathrm{Fe}(\mathrm{DPM})_{3}+3 \mathrm{HCl} .
$$

Specific experimental conditions for deposition of iron oxide films in different schemes and Co-modified films are given below.

(i) Three-step scheme: The iron oxide films were deposited in the cold-wall-type atmospheric CVD reactor at a substrate temperature in the range of $350-450^{\circ} \mathrm{C}$. Precursor $\left[\mathrm{Fe}(\mathrm{acac})_{3}\right.$ ] evaporation temperature was $\approx 190^{\circ} \mathrm{C}$. As-deposited films were first reduced and then oxidized by annealing in $\mathrm{H}_{2}$ and oxygen ambients respectively in a separate furnace. The reduction was performed in $\mathrm{H}_{2}$ ambient at $350^{\circ} \mathrm{C}$ for $-5 \mathrm{~h}$, Oxidation was accomplished in oxygen ambient for $3 \mathrm{~h}$ at $350^{\circ} \mathrm{C}$.

(ii) Two-step scheme: The iron oxide films were deposited in the resistively heated LPCVD reactor at a substrate temperature in the range of $500-550^{\circ} \mathrm{C}$. Source $\left[\mathrm{Fe}(\mathrm{DPM})_{3}\right]$ evaporation temperature was $\approx 165^{\circ} \mathrm{C}$. Films were deposited at a pressure of 0.5 torr of Ar which also acted as the carrier gas. The flow rate of $\mathrm{Ar}$ was kept constant and outlet port pumping rate was controlled to maintain the pressure for transporting $\mathrm{Fe}(\mathrm{DPM})_{3}$ vapour to the reaction zone. Thickness of the deposited films was measured by the stylus technique and varied between 800 and 
Table 1. Film compositions with respect to cobalt content (at \%) in the film.

\begin{tabular}{lc}
\hline Cobalt (at $\%)$ & $x$ in $\mathrm{Fe}_{2-x} \mathrm{Co}_{x} \mathrm{O}_{3-3}$ \\
\hline 0.0 & 0.0 \\
0.5 & 0.02 \\
2.0 & 0.09 \\
4.0 & 0.17 \\
6.0 & 0.26 \\
\hline
\end{tabular}

$1600 \AA$. As-deposited $\mathrm{Fe}_{3} \mathrm{O}_{4}$ films were annealed in $\mathrm{O}_{2}$ ambient at $350^{\circ} \mathrm{C}$ for $3 \mathrm{~h}$ in order to form $\gamma-\mathrm{Fe}_{2} \mathrm{O}_{3}$ films.

(iii) Single-step scheme: Iron oxide films were deposited in the cold-wall-type atmospheric $\mathrm{CVD}$ reactor at a substrate temperature of $500^{\circ} \mathrm{C}$. $\mathrm{Co}(\mathrm{acac})_{2}$ complex was added to the source $\left[\mathrm{Fe}(\mathrm{acac})_{3}\right.$ ] material corresponding to cobalt fraction ranging from 0.5 to 6 at $\%$. Corresponding film compositions are described in table 1 . In some experiments, the as-deposited films were reduced $\left(350^{\circ} \mathrm{C} / 5 \mathrm{~h}\right)$ in $\mathrm{H}_{2}$ and then oxidized $\left(350^{\circ} \mathrm{C} / 3 \mathrm{~h}\right)$ in $\mathrm{O}_{2}$ to confirm the presence of $\gamma-\mathrm{Fe}_{2} \mathrm{O}_{3}$ in those films.

(iv) Cobalt modification in three-step scheme: Cobalt modified iron oxide films were deposited in the atmospheric CVD reactor at a substrate temperature in the range of $350-450^{\circ} \mathrm{C}$. Co(acac $)_{3}$ was coevaporated with $\mathrm{Fe}(\mathrm{acac})_{3}$ at $\approx 190^{\circ} \mathrm{C}$ to add 6 at $\%$ of cobalt in the film $\left(\mathrm{Fe}_{1.78} \mathrm{Co}_{0.22} \mathrm{O}_{2.87}\right)$. As-deposited films were reduced in $\mathrm{H}_{2}$ ambient at $350^{\circ} \mathrm{C}$ for $5 \mathrm{~h}$ and subsequently oxidized at a temperature in the range of $250-450^{\circ} \mathrm{C}$ for $3 \mathrm{~h}$.

The microstructures were analysed by transmission electron microscope (TEM) studies and crystallographic phases were detected by selected area electron diffraction (SAED) and X-ray diffraction studies. Magnetic properties were determined using a vibrating sample magnetometer (VSM: model DMS-1660).

\section{Results and discussion}

\subsection{Compositional analysis}

Figure 3 shows the depth profile of the $2500 \AA$ (corresponding to etch time of 200 sec) iron oxide film as-deposited in the three-step scheme at $T_{s}=450^{\circ} \mathrm{C} .48 \mathrm{at} \%$ of oxygen and $45 \mathrm{at} \%$ of iron were found in the bulk of the film. Carbon stayed as an impurity, at a high level of 40 at $\%$ on the surface of the film. Carbon content went down to $\approx 7$ at $\%$ after $15 \mathrm{sec}$ of etching.

Figure 4 shows the depth profile of the $4000 \AA$ iron oxide film as-deposited in the single-step scheme. The film composition was 44 at $\%$ of oxygen, 42 at $\%$ of iron and 6 at $\%$ of cobalt. Carbon stayed as an impurity, at an appreciably high 80 at $\%$, on the surface of the film. Carbon content went down to $\approx 8$ at $\%$ after $90 \mathrm{sec}$ of etching. 


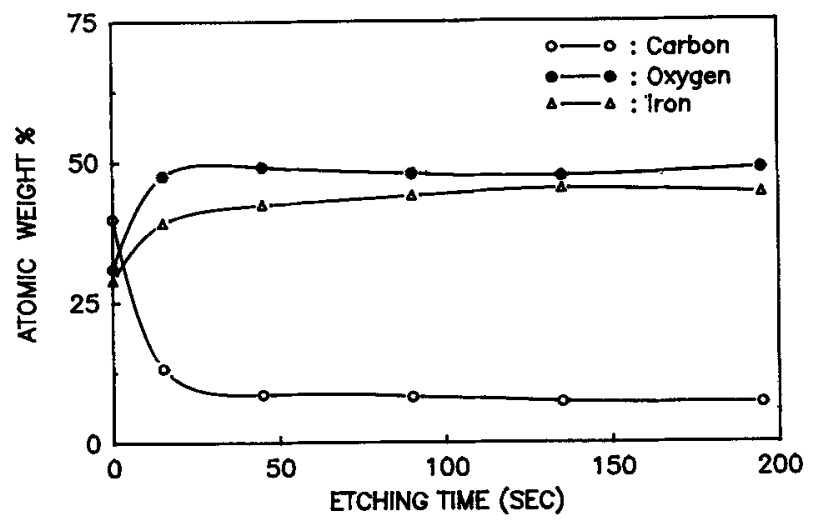

Figure 3. Depth profile analysis of as-deposited iron oxide film grown in the first step of three-step scheme.

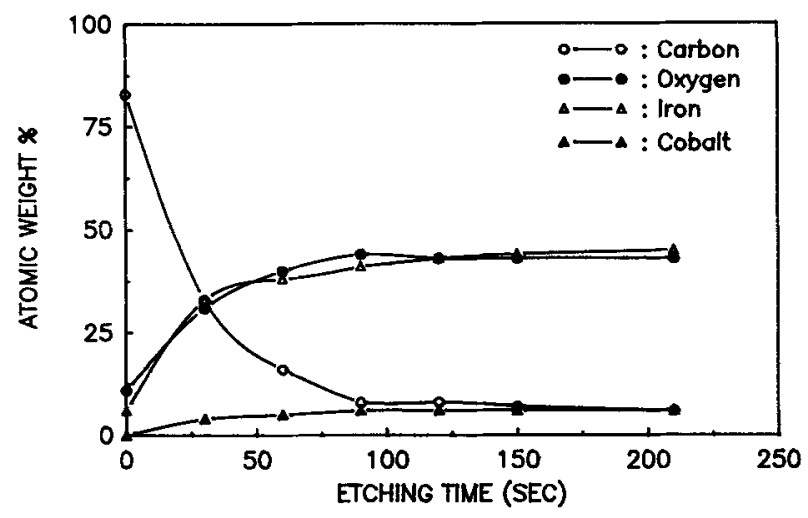

Figure 4. Depth profile analysis of as-deposited Co-doped iron oxide film grown in the single-step scheme.

\subsection{Microstructure and crystalline phases}

\section{2a Structural evolution of $\gamma-\mathrm{Fe}_{2} \mathrm{O}_{3}$ phase from $\alpha-\mathrm{Fe}_{2} \mathrm{O}_{3}$}

Three-step scheme: We have studied the structural transformation of as-deposited $\alpha-\mathrm{Fe}_{2} \mathrm{O}_{3}$ phase to $\gamma-\mathrm{Fe}_{2} \mathrm{O}_{3}$ phase by successive reduction and oxidation treatment. A detailed crystallographic structural analysis of the electron diffraction patterns of iron oxide films deposited under different conditions showed that as-deposited films always formed in the $\alpha-\mathrm{Fe}_{2} \mathrm{O}_{3}$ phase, irrespective of the substrate temperature. Asdeposited films generally consisted of nodular crystallites. These crystallites were well dispersed and at some places formed clusters. Clearly, this appears to be a consequence of the modified deposition mechanisms, discussed in the section dealing with the growth model.

When the as-deposited films were subjected to reduction-oxidation treatment in order to crystallize the $\gamma$-phase of $\mathrm{Fe}_{2} \mathrm{O}_{3}$ with the formation of an intermediate $\mathrm{Fe}_{3} \mathrm{O}_{4}$ phase after the reduction treatment, the morphology of the deposits did not undergo 


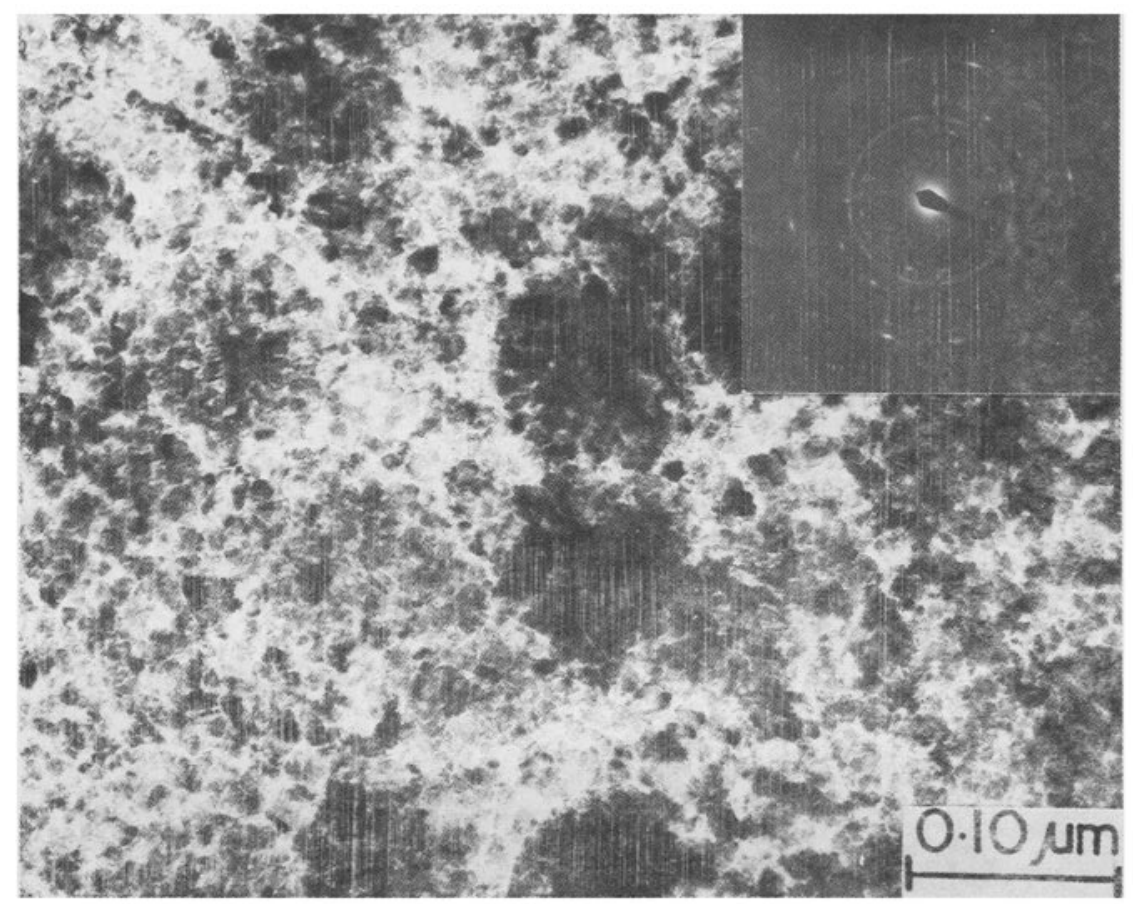

Figure 5. Transmission electron micrograph showing microstructure of $\gamma$ - $\mathrm{Fe}_{2} \mathrm{O}_{3}$ film grown in three-step scheme. Corresponding electron diffraction pattern is shown in the inset.

any significant change. Small increase in crystallite size was, however, observed which can be attributed to possible grain growth or homogenization. Figure 5 shows microstructures of the iron oxide thin film in the $\gamma-\mathrm{Fe}_{2} \mathrm{O}_{3}$ phase obtained after an oxidation at $300^{\circ} \mathrm{C}$ of the as-deposited films. Highly oriented crystallite structure could be characterized by diffraction spots in oxidized films (inset of figure 5). Analysis of the diffraction pattern of the $\gamma-\mathrm{Fe}_{2} \mathrm{O}_{3}$ film indicated that these films consisted of essentially the iron-rich $\gamma-\mathrm{Fe}_{2} \mathrm{O}_{3}$ phase. When interpreted in terms of the depnsition mechanism in a cold-wall-type reactor chamber, it implies an insufficient oxidation of the $\mathrm{Fe}^{3+}$ ions depositing on the substrate from the pyrolysis of $\mathrm{Fe}(\mathrm{acac})_{3}$ complex. Characteristic diffraction rings were observed corresponding to diffraction from (220), (311), (400), (440) and (511) crystal planes of $\gamma$-Fe $\mathrm{F}_{2} \mathrm{O}_{3}$ films. Derivation of the lattice parameter from the diffraction data yielded a value of $8.37 \AA$ which is in between the lattice parameters for iron oxide in stoichiometric $\mathrm{Fe}_{3} \mathrm{O}_{4}$ phase $(8.397 \AA)$ and $\gamma-\mathrm{Fe}_{2} \mathrm{O}_{3}$ phase (8.34 $\AA$ ). An intermediate value of the lattice parameter of $\gamma-\mathrm{Fe}_{2} \mathrm{O}_{3}$ film indicates that these films were oxygen-deficient (Ohta and Terada 1986).

\section{2b Structural transformation of as-deposited $\mathrm{Fe}_{3} \mathrm{O}_{4}$ to $\gamma-\mathrm{Fe}_{2} \mathrm{O}_{3}$}

Two-step scheme: We have studied the crystallographic structure of as-deposited $\mathrm{Fe}_{3} \mathrm{O}_{4}$ and oxidized $\gamma-\mathrm{Fe}_{2} \mathrm{O}_{3}$ phase. Small-angle X-ray diffraction pattern of the as-deposited film (figure $6 \mathrm{a}$ ) shows the peaks corresponding to $(\mathrm{hkl})$ planes $(22 \mathrm{n})$ (222), (311), (400), (511) and (440). These were interpreted to belong to magnetite $\left(\mathrm{Fe}_{3} \mathrm{O}_{4}\right)$ phase. Observation of a weak fingerprint line from (222) plane provided 

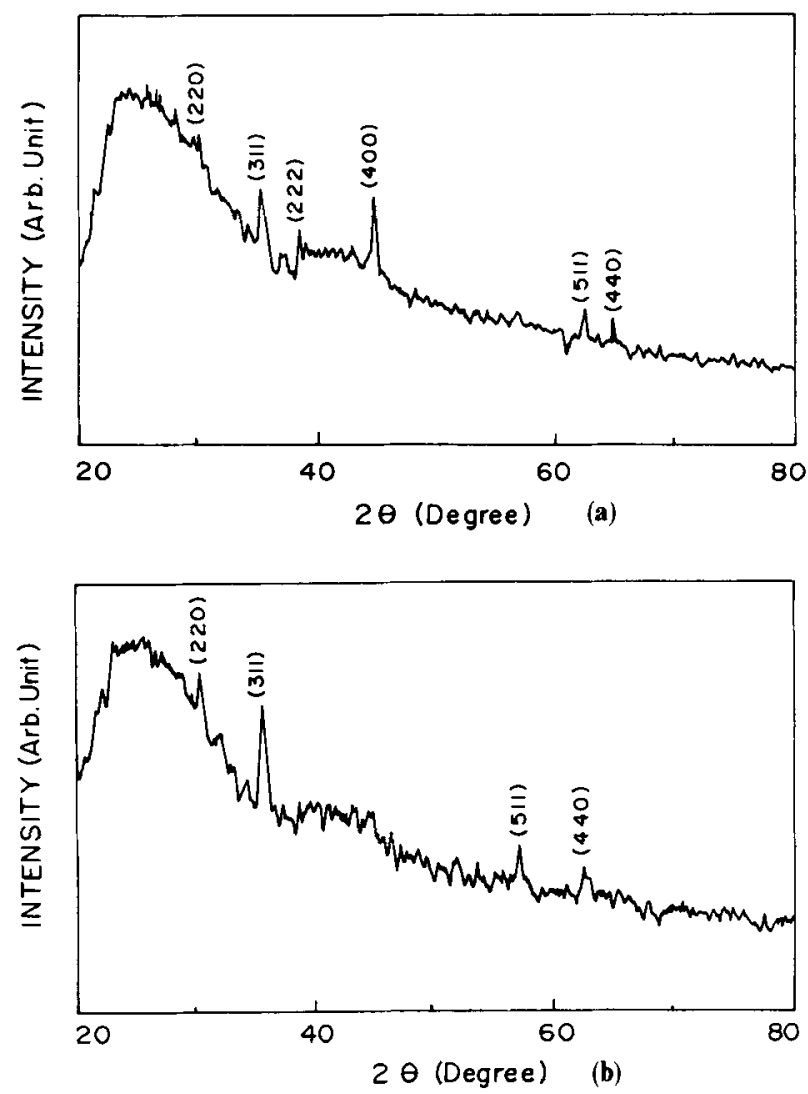

Figure 6. X-ray diffraction pattern of iron oxide films grown in two-step scheme for (a) as-deposited $\mathrm{Fe}_{3} \mathrm{O}_{4}$ and (b) oxidized $\gamma-\mathrm{Fe}_{2} \mathrm{O}_{3}$ phases.

further confirmation of the $\mathrm{Fe}_{3} \mathrm{O}_{4}$ phase in the as-deposited films. Lattice parameter calculated from this data was $8.48 \AA$. A comparison with standard lattice parameter value of $8.397 \AA$ for stoichiometric bulk $\mathrm{Fe}_{3} \mathrm{O}_{4}$ phase shows that it is on the higher side. This indicates the presence of some oxygen deficiency in what was essentially a $\mathrm{Fe}_{3} \mathrm{O}_{4}$ film. The X-ray diffraction pattern of the oxidized film (figure 6b) shows the peaks corresponding to $(220),(311),(511)$ and $(440)$ reflections indicating formation of $\gamma-\mathrm{Fe}_{2} \mathrm{O}_{3}$ phase in the oxidized film. The lattice parameter calculated from diffraction data was $8 \cdot 35 \AA$ which is close to that reported for bulk $\gamma-\mathrm{Fe}_{2} \mathrm{O}_{3}$ phase $(8 \cdot 34 \AA)$. Growth of stoichiometric $\gamma-\mathrm{Fe}_{2} \mathrm{O}_{3}$ phase on oxidation clearly established that as-deposited film contained mainly the $\mathrm{Fe}_{3} \mathrm{O}_{4}$ phase.

\section{$3.2 \mathrm{c}$ Direct growth of $\gamma-\mathrm{Fe}_{2} \mathrm{O}_{3}$ phase and its structural confirmation}

Single-step scheme: In general, iron oxide films deposited at substrate temperature $\left(T_{\mathrm{s}}\right)$ between 300 and $500^{\circ} \mathrm{C}$ consisted of mainly $\alpha-\mathrm{Fe}_{2} \mathrm{O}_{3}$ phase as revealed by the electron diffraction analysis. A direct growth of $y-\mathrm{Fe}_{2} \mathrm{O}_{3}$ film occurs when the deposition is carried out at substrate temperature $T_{\mathrm{s}} \geqslant 500^{\circ} \mathrm{C}$. The electron diffraction pattern (inset of figure 7) consists of sharp rings and spots which clearly show that $\gamma-\mathrm{Fe}_{2} \mathrm{O}_{3}$ films are highly oriented with large crystallite size. In addition to diffraction 


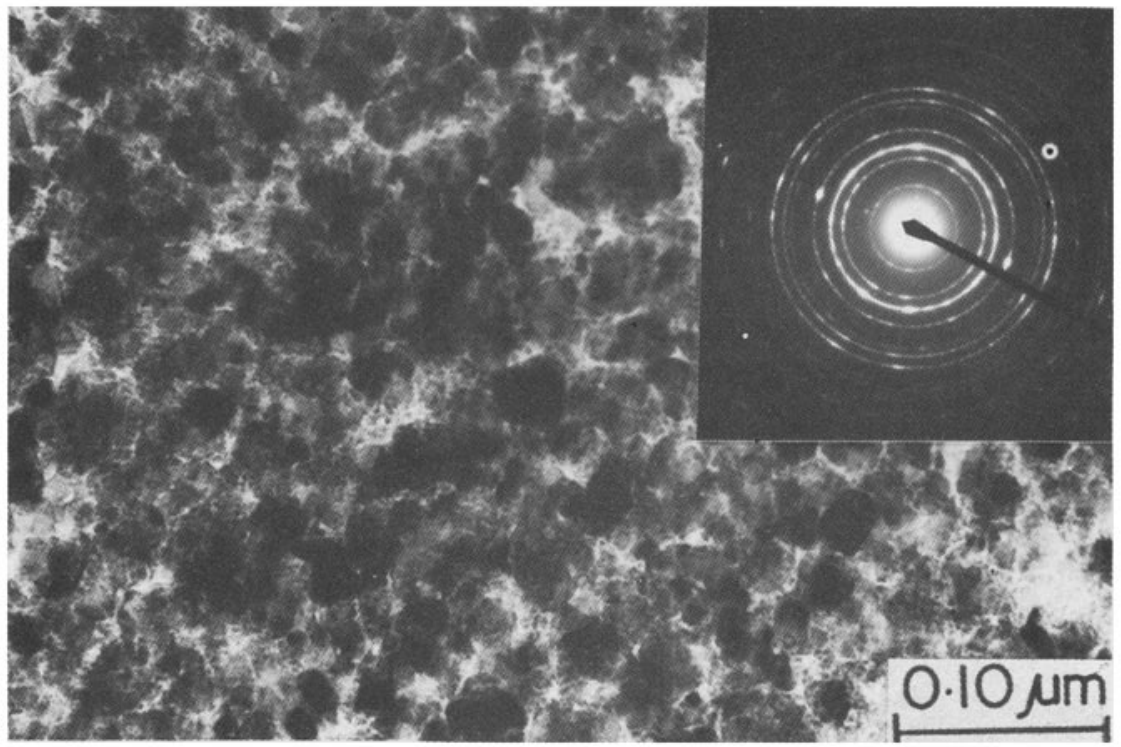

Figure 7. Transmission electron micrograph showing microstructure of as-deposited $\hat{\imath}-\mathrm{Fe}_{2} \mathrm{O}_{3}$ film grown in single-step scheme. Corresponding electron diffraction pattern is shown in the inset.

rings corresponding to (110), (220), (311), (400), (511) and (440) planes, characteristic superlattice diffraction from (211) plane clearly establishes that $y-\mathrm{Fe}_{2} \mathrm{O}_{3}$ was the dominant growth phase. Microstructure of $\gamma-\mathrm{Fe}_{2} \mathrm{O}_{3}$ films (figure 7) is granular with well-compacted grains of average dimension $430( \pm 80) \AA$. The lattice constant of the $\gamma-\mathrm{Fe}_{2} \mathrm{O}_{3}$ phase in the as-deposited films as calculated from diffraction data was typically $8.375 \AA$. This is somewhat higher in comparison with that for bulk $\gamma-\mathrm{Fe}_{2} \mathrm{O}_{3}$ $(8.34 \AA)$ which implies a deficiency in oxygen or the presence of minor components of less oxidized phases in what was essentially the $\gamma-\mathrm{Fe}_{2} \mathrm{O}_{3}$ film. In fact, additional lines in the diffraction pattern corresponding to $(h k l)$ lines of (222) and (444) for $\mathrm{Fe}_{3} \mathrm{O}_{4}$ phase were also observed. To confirm that $\gamma-\mathrm{Fe}_{2} \mathrm{O}_{3}$ was the main growth phase, the as-deposited films were first reduced in hydrogen at $350^{\circ} \mathrm{C}$ for $5 \mathrm{~h}$ and then reoxidized at $350^{\circ} \mathrm{C}$ for $3 \mathrm{~h}$ in oxygen. Electron diffraction studies of films after hydrogen reduction show most of the main $\mathrm{Fe}_{3} \mathrm{O}_{4}$ diffraction rings including the fingerprint diffraction ring corresponding to the (222) reflection. The lattice parameter as calculated from diffraction analysis of the reduced film was $8.405 \AA$ which agreed well with standard values for $\mathrm{Fe}_{3} \mathrm{O}_{4}$ phase in the reduced films. Electron diffraction data confirmed that, on reoxidation, as one should expect, these films reverted to the $\gamma-\mathrm{Fe}_{2} \mathrm{O}_{3}$ phase. This study clearly established that as-deposited films were $\gamma-\mathrm{Fe}_{2} \mathrm{O}_{3}$.

\section{2d Structures of cobalt-modified iron oxide films}

Under most general growth conditions undoped iron oxide films formed by CVD process are in the form of $\alpha-\mathrm{Fe}_{2} \mathrm{O}_{3}$ phase. Incorporation of $\mathrm{Co}^{2+}$ ions in the film during the growth stage does not have any effect on the crystallographic phase of the deposited film. Consequently no discernible improvement in the magnetic properties 


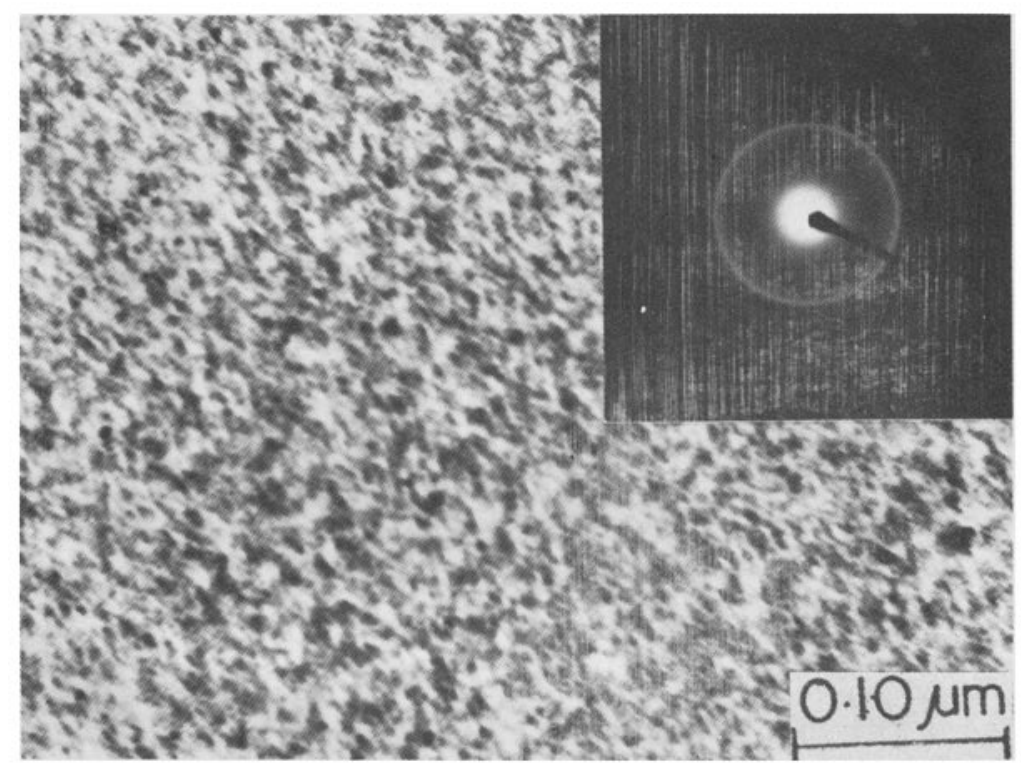

Figure 8. Transmission electron micrograph showing microstructure of Co-modified $\gamma-\mathrm{Fe}_{2} \mathrm{O}_{3}$ film. Corresponding electron diffaction pattern is shown in the inset.

of the Co-modified iron oxide films were observed. Co-modified iron oxide films just as in the undoped case were required to be subjected to a $\mathrm{H}_{2}$ reduction and controlled oxidation sequence in order to achieve the magnetic $\gamma-\mathrm{Fe}_{2} \mathrm{O}_{3}$ phase. Figure 8 shows microstructure and corresponding electron diffraction pattern for Co-modified $\gamma-\mathrm{Fe}_{2} \mathrm{O}_{3}$ films. Fine grain and generally defect-riddled microstructure of as-deposited film transformed to a compact granular structure in the $\mathrm{Fe}_{3} \mathrm{O}_{4}$ phase. A detailed study of the oxidation behaviour using electron diffraction pattern indicated that a large fraction of the reduced film was transformed to $\gamma-\mathrm{Fe}_{2} \mathrm{O}_{3}$ phase at a threshold oxidation temperature, $T_{\mathrm{ox}}$, of $250^{\circ} \mathrm{C}$. Oxidation at above the threshold temperature in the range $250^{\circ} \mathrm{C}<T_{o x}<450^{\circ} \mathrm{C}$ was generally accompanied by considerable grain growth in the $\gamma-\mathrm{Fe}_{2} \mathrm{O}_{3}$ film. Directly reduced $\mathrm{Fe}_{3} \mathrm{O}_{4}$ film showed spinel structure as evidenced from the diffraction analysis. Oxidation of these films under steady-state conditions leading to transformation to $\gamma-\mathrm{Fe}_{2} \mathrm{O}_{3}$ phase was established by diffraction rings (inset of figure 8) corresponding to (111), (220), (311), (400), (511) along with superlattice reflections from the plane (211). The lattice parameter for a typical $\gamma-\mathrm{Fe}_{2} \mathrm{O}_{3}$ film is $8.34 \AA$. This agrees well with the standard value of $8.339 \AA$ for bulk $\gamma-\mathrm{Fe}_{2} \mathrm{O}_{3}$ suggesting that $\gamma-\mathrm{Fe}_{2} \mathrm{O}_{3}$ films were synthesized by controlled oxidation of $\mathrm{Fe}_{3} \mathrm{O}_{4}$ films.

\subsection{Magnetic properties}

\section{3a $M-H$ loop characteristics}

(i) Three-step scheme: As-deposited iron oxide films, irrespective of deposition temperature, were weakly ferromagnetic being essentially in the $\alpha-\mathrm{Fe}_{2} \mathrm{O}_{3}$ phase. These 


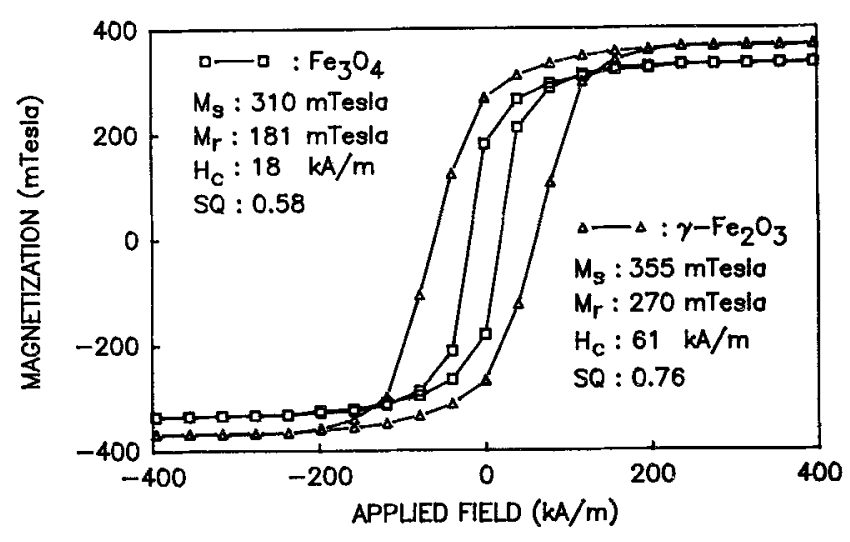

Figure 9. Characteristic $M-H$ loops of reduced $\mathrm{Fe}_{3} \mathrm{O}_{4}$ and oxidized $\gamma-\mathrm{Fe}_{2} \mathrm{O}_{3}$ films grown in three-step scheme. Magnetic properties are shown in the inset.

films on reduction to the $\mathrm{Fe}_{3} \mathrm{O}_{4}$ phase showed a saturation magnetization $\left(\mu_{0} M_{\mathrm{s}}\right)$ value of $310 \mathrm{mT}$, remanent magnetization $\left(M_{\mathrm{r}}\right)$ value of $181 \mathrm{mT}$, and coercivity $\left(H_{\mathrm{c}}\right)$ value of $18 \mathrm{kA} / \mathrm{m}$ (figure 9). On oxidation to form $\gamma-\mathrm{Fe}_{2} \mathrm{O}_{3}$ phase the $M_{\mathrm{r}}$ and $H_{\mathrm{c}}$ values of the films increased to $270 \mathrm{mT}$ and $61 \mathrm{kA} / \mathrm{m}$. Squareness ratio $\left(\mathrm{SQ}=M_{\mathrm{r}} / M_{\mathrm{s}}\right)$ of the $\mathrm{Fe}_{3} \mathrm{O}_{4}$ film was 0.58 . After oxidation, the $\mathrm{SQ}$ for $\gamma-\mathrm{Fe}_{2} \mathrm{O}_{3}$ films increased to a considerably high value of 0.76 . The coercive squareness $\left(S^{*}\right)$ which provides a measure of slant of the $M-H$ loop and is given by

$$
S^{*}=1-\left(\frac{M_{\mathrm{r}}}{H_{\mathrm{c}}}\right)\left(\frac{1}{\text { slope at } H_{\mathrm{c}}}\right),
$$

has also been measured to be 0.30 for the $\gamma-\mathrm{Fe}_{2} \mathrm{O}_{3}$ films. Enhancement in $M_{\mathrm{r}}, H_{\mathrm{c}}$ and SQ parameters in $\gamma-\mathrm{Fe}_{2} \mathrm{O}_{3}$ is attributed to introduction of strong anisotropy in the film. It is apparent that the changes in the microstructure of the film could also be responsible for it. This is discussed in the growth model section.

(ii) Two-step scheme: Figure 10 shows a comparison of typical hysteresis loops for the as-deposited $\mathrm{Fe}_{3}, \mathrm{O}_{4}$ and oxidized $\gamma-\mathrm{Fe}_{2} \mathrm{O}_{3}$ films. Increase in $\mathrm{H}_{\mathrm{c}}$ from $93 \mathrm{kA} / \mathrm{m}$ for as-deposited $\mathrm{Fe}_{3} \mathrm{O}_{4}$ film to $122 \mathrm{kA} / \mathrm{m}$ for oxidized $\gamma-\mathrm{Fe}_{2} \mathrm{O}_{3}$ film is attributed to anisotropy introduced by redistribution of $\mathrm{Fe}^{3+}$ and vacancies among octahedral and tetrahedral sites of spinel lattice. $\gamma-\mathrm{Fe}_{2} \mathrm{O}_{3}$ showed $M_{\mathrm{r}}$ and $\mathrm{SQ}$ values of $102 \mathrm{mT}$ and 0.80 respectively.

(iii) Magnetic properties of directly deposited Co-doped $\gamma-\mathrm{Fe}_{2} \mathrm{O}_{3}$ films-single-step scheme: The magnetic properties of the directly deposited $\gamma-\mathrm{Fe}_{2} \mathrm{O}_{3}$ films were in general superior to the conventionally formed $\gamma-\mathrm{Fe}_{2} \mathrm{O}_{3}$ films through a reduction-oxidation process. This is attributed to the fractional variations in the partial presence of $\mathrm{Fe}_{3} \mathrm{O}_{4}$ phase in $\gamma-\mathrm{Fe}_{2} \mathrm{O}_{3}$. Figure 11 shows characteristic $M-H$ loop of $\gamma-\mathrm{Fe}_{2} \mathrm{O}_{3}$ films containing 6 at $\%$ of cobalt directly deposited at substrate temperature of $\approx 500^{\circ} \mathrm{C}$. The inferred magnetic parameters are shown in the inset. Typically the $H_{c}$ values of directly deposited $\gamma-\mathrm{Fe}_{2} \mathrm{O}_{3}$ films ranged from 119 to 237 $\mathrm{kA} / \mathrm{m}$ depending upon the cobalt concentration in the film with highest $H_{\mathrm{c}}$ of $237 \mathrm{kA} / \mathrm{m}$. This film showed $M_{\mathrm{r}}$, SQ and $S^{*}$ values of $281 \mathrm{mT}, 0.83$ and 0.60 , 


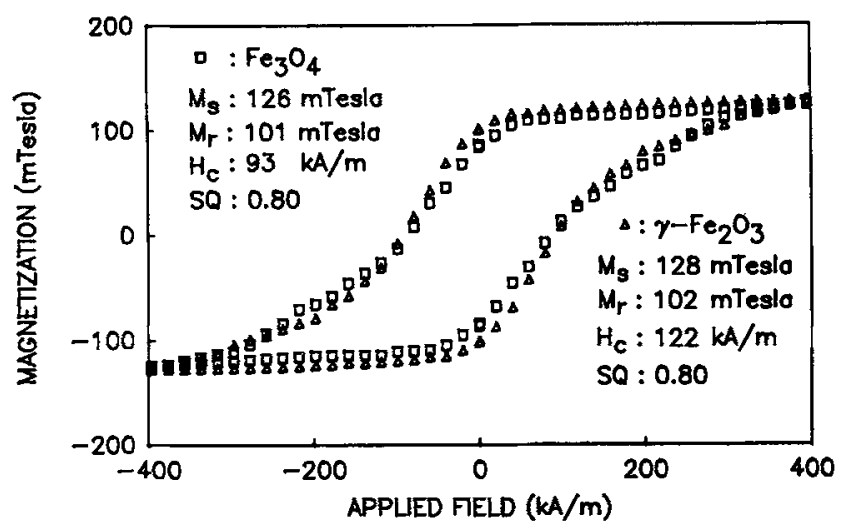

Figure 10. Characteristic $\mathrm{M}-\mathrm{H}$ loops of as-deposited $\mathrm{Fe}_{3} \mathrm{O}_{4}$ and oxidized $\gamma-\mathrm{Fe}_{2} \mathrm{O}_{3}$ films grown in two-step scheme. Magnetic properties are shown in the inset.

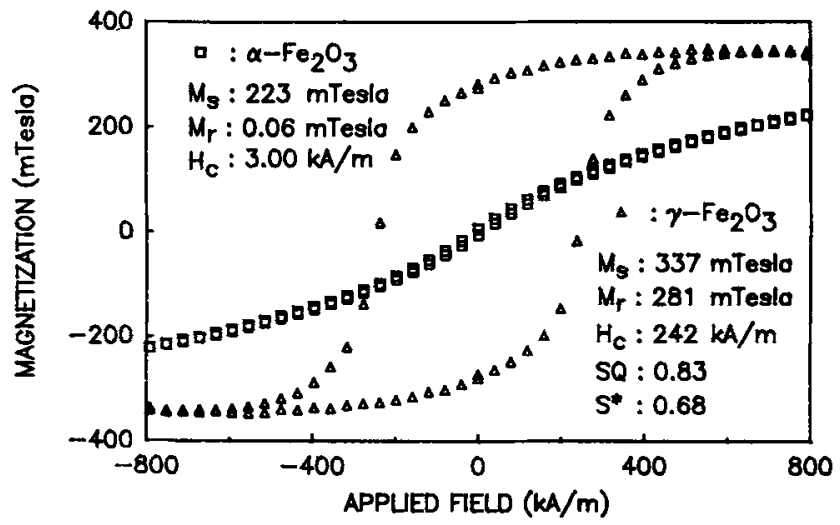

Figure 11. Characteristic $M-H$ loops of iron oxide films containing 6 at $\%$ cobalt for directly deposited $\gamma-\mathrm{Fe}_{2} \mathrm{O}_{3}$ at $T_{\mathrm{s}}=500^{\circ} \mathrm{C}$ and as-deposited $\alpha-\mathrm{Fe}_{2} \mathrm{O}_{3}$ films at $T_{3}=400^{\circ} \mathrm{C}$. Magnetic properties are shown in the inset.

respectively, which are higher than those of the r.f. sputtered films (Ohta and Terada 1986).

High coercivity values of directly deposited $\gamma-\mathrm{Fe}_{2} \mathrm{O}_{3}$ at $T_{\mathrm{s}}=500^{\circ} \mathrm{C}$ underwent a deterioration upon reduction due to transformation to a $\mathrm{Fe}_{3} \mathrm{O}_{4}$ phase. Reoxidation to $\gamma-\mathrm{Fe}_{2} \mathrm{O}_{3}$ phase improved the properties but these remained inferior to those of the directly as-deposited film. In contrast, the $\alpha-\mathrm{Fe}_{2} \mathrm{O}_{3}$ films formed at a lower deposition temperature of $400^{\circ} \mathrm{C}$ showed considerable improvement in $H_{c}$ values as reduction led to growth of $\mathrm{Fe}_{3} \mathrm{O}_{4}$ phase. These results confirmed the formation of $\gamma-\mathrm{Fe}_{2} \mathrm{O}_{3}$ phase as concluded from the crystallographic studies.

In order to explore the nature of the anisotropy introduced by cobalt in these films, biaxial vector coil measurements were performed (Ouchi and Iwasaki 1988). To carry out biaxial magnetic measurements, two orthogonal sets of sensing coils were used in VSM. The magnetization vectors at different film orientation angles $(\Omega)$ between 0 and $180^{\circ}$ with respect to the direction of applied magnetic field $\left(H_{\mathrm{a}}\right)$ were determined by measuring the parallel $\left(M_{X}\right)$ and perpendicular $\left(M_{Y}\right)$ components 


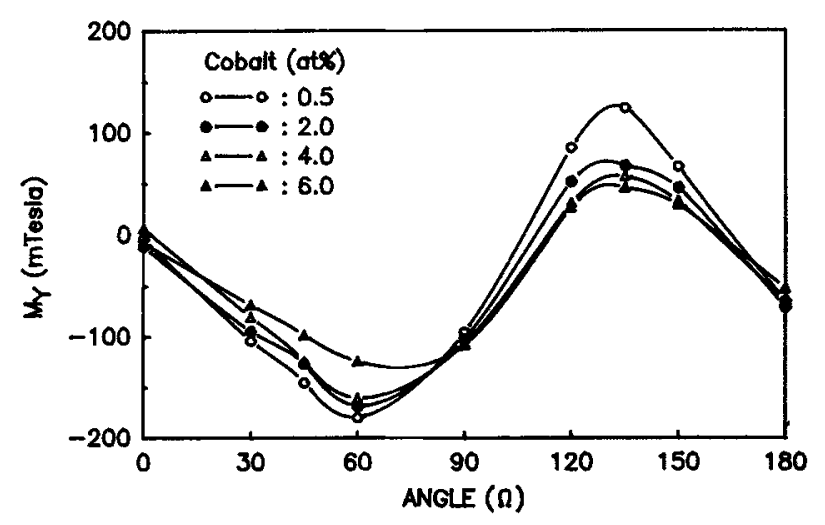

Figure 12. Variation of magnetization $\left(M_{Y}\right)$ perpendicular to applied field direction at different orientation angles $(\Omega)$ for Co-doped $\gamma-\mathrm{Fe}_{2} \mathrm{O}_{3}$ films grown in single-step scheme.

of magnetization. From these sets of data, the magnetization in the plane of the film $\left(M_{L}\right)$ and that perpendicular to the film plane $\left(M_{V}\right)$ could also be computed as a function of $\Omega$. Anisotropy energy $(K)$ in the film can be calculated from these data. These measurements have shown that the direction of anisotropy lies in the film plane. Variation of $M_{Y}$ with $\Omega$ has been studied for $\gamma-\mathrm{Fe}_{2} \mathrm{O}_{3}$ films with $0.5-6$ at $\%$ cobalt (figure 12). Symmetric variation of $M_{Y}$ was observed for the films in the $0-90^{\circ}$ and $90-180^{\circ}$ range which indicated magnetocrystalline anisotropy arising from the cobalt present in the film.

(iv) Magnetic properties of heterogeneously dispersed Co-modified iron oxide films: Figure 13 shows typical hysteresis loops for the reduced $\mathrm{Fe}_{3} \mathrm{O}_{4}$ and $\gamma-\mathrm{Fe}_{2} \mathrm{O}_{3}$ films. The remanent magnetization, coercive force and squareness ratio of the $\gamma-\mathrm{Fe}_{2} \mathrm{O}_{3}$ films were observed to be $220 \mathrm{mT}, 65 \mathrm{kA} / \mathrm{m}$ and 0.60 respectively. These values are higher than those for $\mathrm{Fe}_{3} \mathrm{O}_{4}$ films $S^{*}$ parameter close to 0.40 was obtained for both films.

As discussed earlier extensive transformation of $\mathrm{Fe}_{3} \mathrm{O}_{4}$ film to $\gamma-\mathrm{Fe}_{2} \mathrm{O}_{3}$ phase takes place even at a moderate temperature of $250^{\circ} \mathrm{C}$. However, it was found that oxidation at higher temperature $\left(>250-450^{\circ} \mathrm{C}\right)$ had profound effect on the magnetic properties of Co-modified $\gamma-\mathrm{Fe}_{2} \mathrm{O}_{3}$ films. The transformation of $\mathrm{Fe}_{3} \mathrm{O}_{4}$ film to $\gamma-\mathrm{Fe}_{2} \mathrm{O}_{3}$ phase by $250^{\circ} \mathrm{C}$ oxidation did not significantly improve the $M_{\mathrm{r}}$ value which changed from $156 \mathrm{mT}$ for Co-modified $\mathrm{Fe}_{3} \mathrm{O}_{4}$ to $161 \mathrm{mT}$ for Co-modified $\gamma-\mathrm{Fe}_{2} \mathrm{O}_{3}$. Clearly, therefore, $\mathrm{Co}^{2+}$ ion positions in the $\gamma$-phase are not affected much during the $250^{\circ} \mathrm{C}$ oxidation process. The magnetic properties of Co-modified iron oxide films in the $\gamma-\mathrm{Fe}_{2} \mathrm{O}_{3}$ form were strongly dependent on the oxidation temperatures. Figure 14 shows the variation of magnetic coercivity in the film plane $\left[H_{c}(\|)\right]$ and perpendicular to the film plane $\left[H_{\mathrm{c}}(\perp)\right]$ with the oxidation temperature. The incremental changes in the $H_{c}(\|)$ show two distinct regions marked by different slopes indicating two different mechanisms of $H_{c}$ enhancement. For the Co-modified $\gamma-\mathrm{Fe}_{2} \mathrm{O}_{3}$ film formed at $250^{\circ} \mathrm{C}$, an initial high value of coercivity of $33 \mathrm{kA} / \mathrm{m}$ was obtained. This value further increased by a factor of two to $65 \mathrm{kA} / \mathrm{m}$ when oxidation was carried out at $350^{\circ} \mathrm{C}$. It may be noted that these $H_{\mathrm{c}}$ values were quite high in comparison with a minimum $H_{c}$ of $44 \mathrm{kA} / \mathrm{m}$ obtained in earlier studies for Co-doped, $49 \mathrm{kA} / \mathrm{m}$ for epitaxial Co-ferrites and $59 \mathrm{kA} / \mathrm{m}$ for Co-adsorbed iron oxide. Such high coercivity values obtained in our CVD prepared films are attributed to an increase in the 


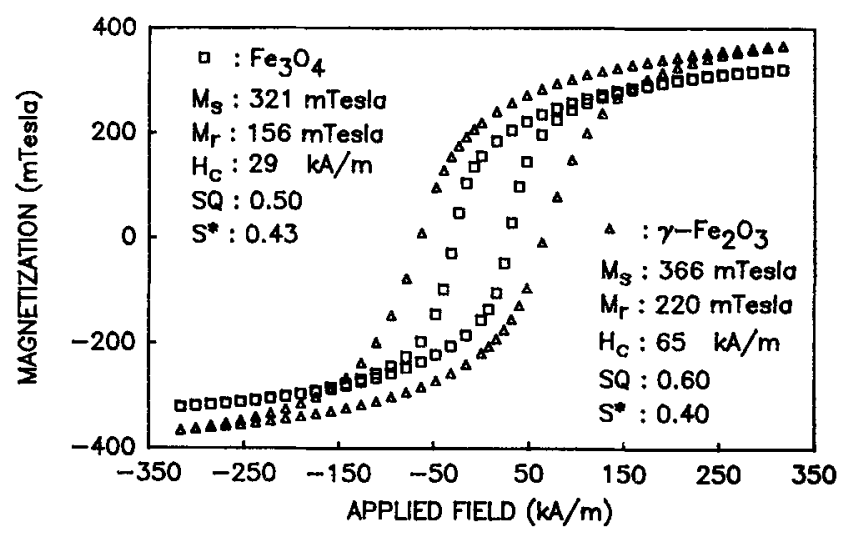

Figure 13. Characteristic $M-H$ loops of Co-modified iron oxide films for reduced $\mathrm{Fe}_{3} \mathrm{O}_{4}$ and oxidized $\gamma-\mathrm{Fe}_{2} \mathrm{O}_{3}$ films. Magnetic properties are shown in the inset.

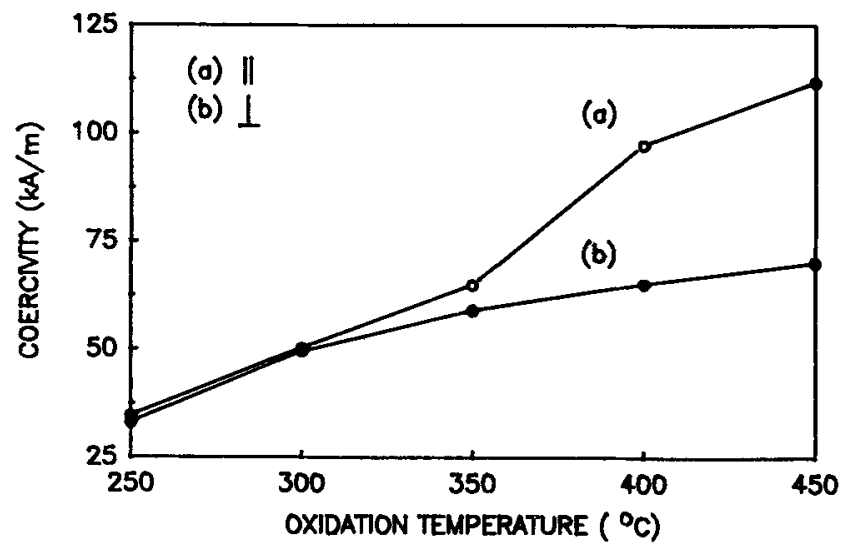

Figure 14. Dependence of coercivity (a) in the plane and (b) perpendicular to the plane of the $\gamma-\mathrm{Fe}_{2} \mathrm{O}_{3}$ film on oxidation temperature.

anisotropy from microstructured $\mathrm{Co}$-inclusions in the $\gamma-\mathrm{Fe}_{2} \mathrm{O}_{3}$ film where $\mathrm{Co}^{2+}$ locations differ from those at octahedral sites in the spinel structure and those which are trapped at interstitial locations other than lattice sites of the spinel structure.

Biaxial magnetic measurements were done to understand the above observation of Co-dispersion in $\gamma$ - $\mathrm{Fe}_{2} \mathrm{O}_{3}$ matrix. Figure 15 shows the changes in the $M_{Y}$ component with $\Omega$ at an applied field $\left(H_{\mathrm{a}}\right)$ of $4 \mathrm{kOe}$. An increase in $M_{Y}$ (at $\left.90^{\circ}\right)$ was observed when the oxidation temperature was kept at $350^{\circ} \mathrm{C}$. $\mathrm{Fe}^{2+}$ to $\mathrm{Fe}^{3+}$ transformation and redistribution of $\mathrm{Fe}^{3+}$ and vacancies among tetrahedral and octahedral sites of spinel lattice were responsible for increase in average saturation values (Dhara et al 1992b). Asymmetric nature of the $M_{Y}$ curve in the $0.90^{\circ}$ and 90-180 regions indicated that anisotropies of different physical nature were present in the film. As discussed earlier, heterogeneous nature of the $\mathrm{Co}^{2+}$ dispersions involving $\mathrm{Co}^{2+}$ at octahedral (magnetocrystalline) and interstitial (uniaxial) sites may be partly responsible for this behaviour. Completely different behaviour of $M_{Y}$ in case of $\gamma-\mathrm{Fe}_{2} \mathrm{O}_{3}$ film oxidized at $400^{\circ} \mathrm{C}$ was observed. Not only was the net value 


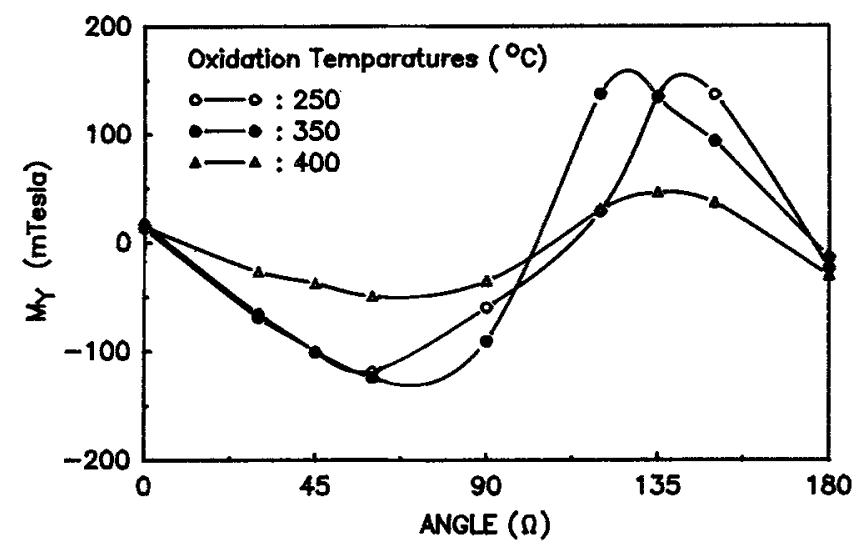

Figure 15. Variation of magnetization $\left(M_{Y}\right)$ perpendicular to applied field direction at different orientation angles $(\Omega)$ for Co-modified $\gamma-\mathrm{Fe}_{2} \mathrm{O}_{3}$.

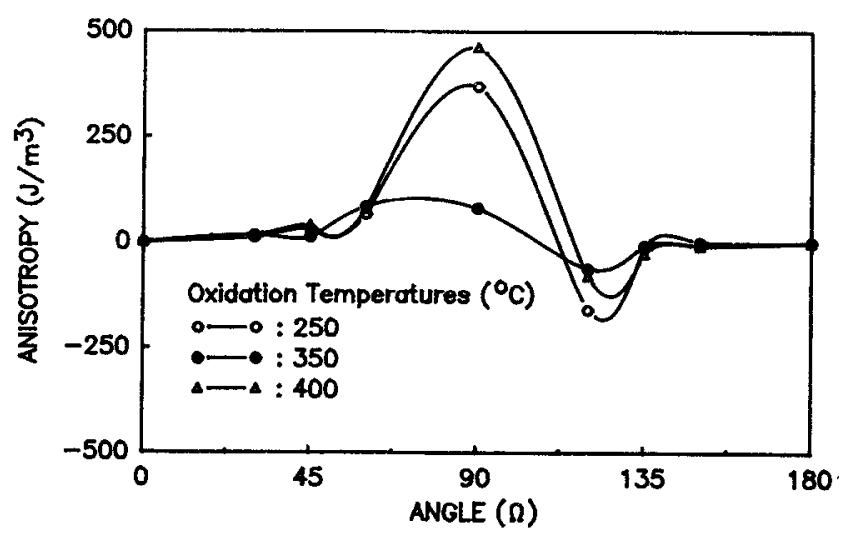

Figure 16. Variation of anisotropy energy at different orientation angles $(\Omega)$ for Co-modified $\gamma-\mathrm{Fe}_{2} \mathrm{O}_{3}$ films.

of $M_{Y}$ (at $90^{\circ}$ ) lower but the angular dependence was more symmetrical (sinusoidal). The $\gamma-\mathrm{Fe}_{2} \mathrm{O}_{3}$ film at this oxidation temperature showed strong magnetocrystalline anisotropy as a result of increase in number of $\mathrm{Co}^{2+}$ ions at cation sites. Consequently a reduction in extent of $\mathrm{Co}^{2+}$ heterogeneity might have led to this behaviour. Anisotropy energy showed a maximum at $271 \mathrm{~J} / \mathrm{m}^{3}$ for a film oxidized at $400^{\circ} \mathrm{C}$. A film with an oxidizing temperature of $250^{\circ} \mathrm{C}$ showed a value of $264 \mathrm{~J} / \mathrm{m}^{3}$ (figure 16). On the other hand, films annealed at $350^{\circ} \mathrm{C}$ showed a low anisotropy value of $81 \mathrm{~J} / \mathrm{m}^{3}$. A confirmation of the heterogeneity model is provided by the studies of variation of coercivity of the Co-modified $\gamma-\mathrm{Fe}_{2} \mathrm{O}_{3}$ films with the orientation angle $\Omega$ as obtained from vector magnetic measurements. This is presented in figure 17. The $H_{\mathrm{c}}$ values for $\gamma-\mathrm{Fe}_{2} \mathrm{O}_{3}$ film formed at low oxidation temperatures $\left(250-350^{\circ} \mathrm{C}\right)$ exhibited a peak at $\Omega$ of $60^{\circ}$. This anisotropic nature is attributed to microstructure-related anisotropy present in the film due to the presence of strong magnetostatic interaction ( $\mathrm{Lu}$ and Charap 1992) in $\gamma-\mathrm{Fe}_{2} \mathrm{O}_{3}$ regions with $\mathrm{Co}^{2+}$ trapped at interstitial and $\mathrm{Co}^{2+}$ at octahedral sites. As the oxidation temperature was increased, the microstructure-related 


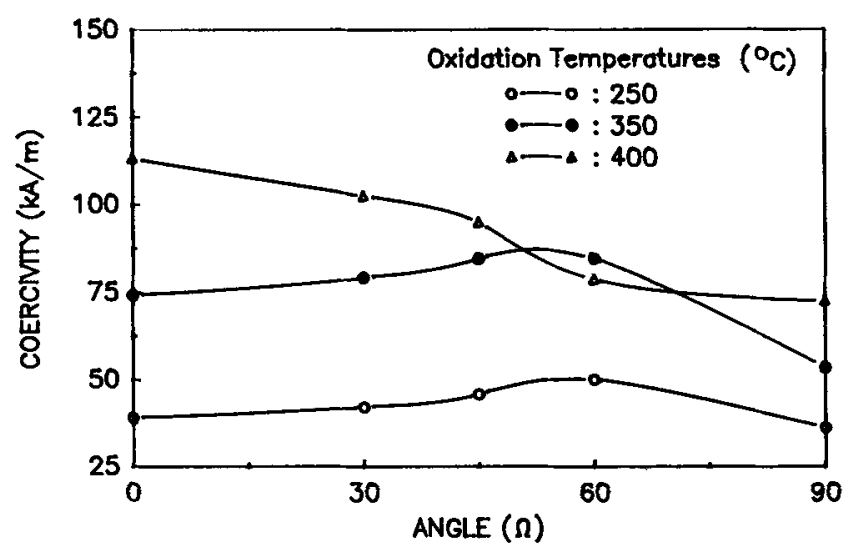

Figure 17. Variation of in-plane coercivity $\left(H_{c}\right)$ at different orientation angles $(\Omega)$ for Co-modified $\gamma-\mathrm{Fe}_{2} \mathrm{O}_{3}$ films.

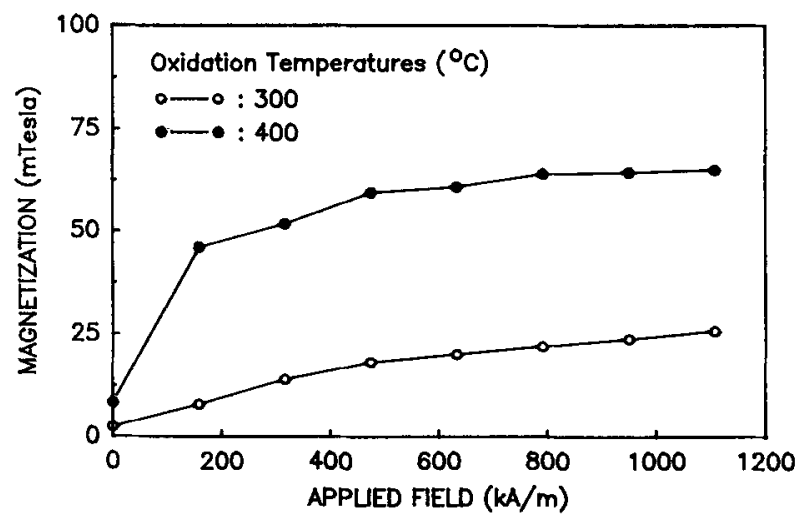

Figure 18. Variation of magnetization with applied field for Co-modified $\gamma-\mathrm{Fe}_{2} \mathrm{O}_{3}$ films.

contribution to anisotropy progressively decreased. As a result, a monotonous decrease in the coercivity for film oxidized at $400^{\circ} \mathrm{C}$ and disappearance of the coercivity maximum in figure 17 was observed. This clearly indicates that contribution to anisotropy is dominated by magnetocrystalline type due to migration of interstitially trapped $\mathrm{Co}^{2+}$ to cation sites (Speliotis and Judge 1991).

The dispersion of cobalt in ferrimagnetic $\gamma-\mathrm{Fe}_{2} \mathrm{O}_{3}$ matrix was studied by measuring magnetization (figure 18 ) at $600^{\circ} \mathrm{C}$ which is more than the Curie temperature $\left(T_{\mathrm{C}}\right)$ of $\gamma-\mathrm{Fe}_{2} \mathrm{O}_{3}$ but lower than that of ferromagnetic cobalt species $\left(T_{\mathrm{C}} \approx 800^{\circ} \mathrm{C}\right)$ of films oxidized at $300^{\circ} \mathrm{C}$ and $400^{\circ} \mathrm{C}$ oxidized films. A higher magnetization value for the films oxidized at $400^{\circ} \mathrm{C}$ than that for the $300^{\circ} \mathrm{C}$ oxidized one indicated that clusters of cobalt were present in the former. On the other hand, lower value of magnetization for $300^{\circ} \mathrm{C}$ oxidized film indicated that cobalt is well dispersed through the entire volume of the specimen. These data lend further support to our earlier conclusions regarding Co-heterogeneity (Beck 1971). 


\section{3b Temperature dependence of coercivity}

(i) Two-step scheme: Coercivity decreased almost linearly with increase in temperature for $\gamma-\mathrm{Fe}_{2} \mathrm{O}_{3}$ films deposited using the two-step scheme (figure 19). In the undoped iron oxide films, only the induced anisotropy, originating from the redistribution of $\mathrm{Fe}^{3+}$ ions and vacancies among octahedral and tetrahedral sites, remains in the film which is not strongly dependent on temperature. Curie temperature of the $\gamma$ - $\mathrm{Fe}_{2} \mathrm{O}_{3}$ films oxidized from directly deposited $\mathrm{Fe}_{3} \mathrm{O}_{4}$ films was found to be $550^{\circ} \mathrm{C}$.

(ii) Nature of anisotropy in directly deposited Co-doped $\gamma-\mathrm{Fe}_{2} \mathrm{O}_{3}$ film-single-step scheme: Temperature dependence of coercivity of the $\gamma-\mathrm{Fe}_{2} \mathrm{O}_{3}$ films deposited in the single-step scheme and containing $0.5-6 \mathrm{at} \%$ of cobalt was studied to find out the nature of anisotropy in the films introduced by $\mathrm{Co}^{2+}$ ions. Figure 20 shows the temperature dependence of $H_{c}$ value of the films with $0.5-6 \mathrm{at} \%$ of cobalt content. Slopes were negative and its magnitude ranging from 10 to 19 (for $T \leqslant 200^{\circ} \mathrm{C}$ ) in the $H_{\mathrm{c}}(T)$ plot (figure 20) indicated that $H_{\mathrm{c}}$ of the films was strongly temperature-

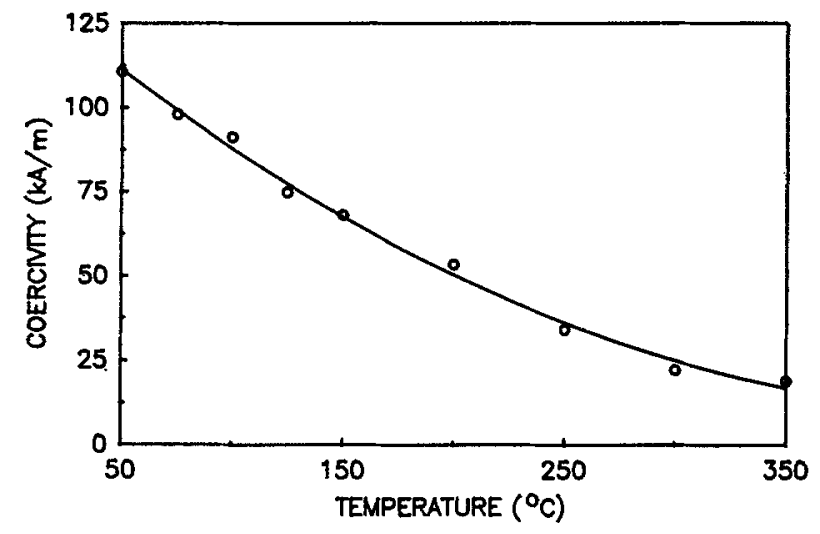

Figure 19. Dependence of coercivity with temperature for $\gamma-\mathrm{Fe}_{2} \mathrm{O}_{3}$ film grown in two-step scheme.

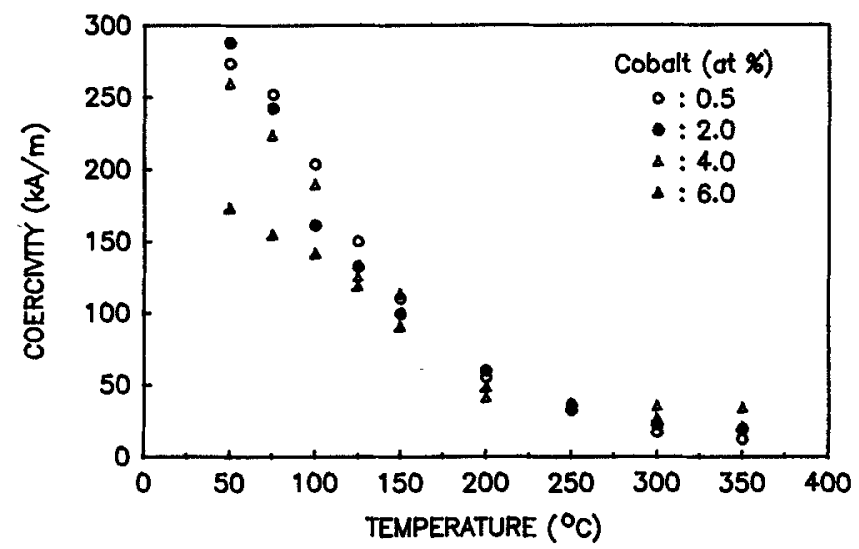

Figure 20. Dependence of coercivity with temperature for $\mathrm{Co}$-doped $\gamma-\mathrm{Fe}_{2} \mathrm{O}_{3}$ films grown in single-step scheme. 


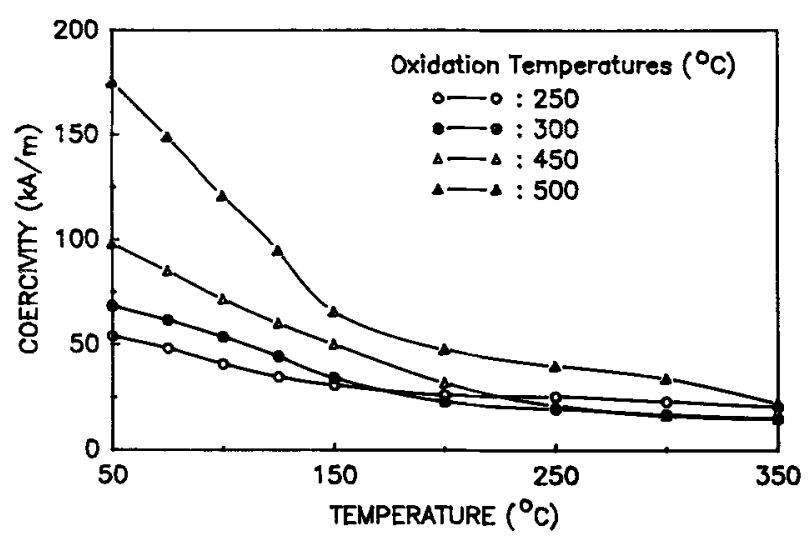

Figure 21. Dependence of coercivity with temperature for Co-modified $\gamma-\mathrm{Fe}_{2} \mathrm{O}_{3}$ films.

dependent. This suggests that magnetocrystalline anisotropy (Meng et al 1987) which has a strong inverse dependence on temperature is present in the directly deposited $\gamma-\mathrm{Fe}_{2} \mathrm{O}_{3}$ films. The magnitude of the slope had the lowest value of 10.55 for $\gamma-\mathrm{Fe}_{2} \mathrm{O}_{3}$ film containing 0.5 at $\%$ cobalt and this value increased with increasing cobalt content in the film as shown in figure 20. Curie temperatures $\left(T_{\mathrm{C}}\right)$ for these directly deposited $\gamma-\mathrm{Fe}_{2} \mathrm{O}_{3}$ films were also studied. It was found that the value of $T_{\mathrm{C}}$ decreased with increasing amount of cobalt in the $\gamma-\mathrm{Fe}_{2} \mathrm{O}_{3}$ matrix. Curie temperature of the film containing 0.5 at $\%$ cobalt was found to be $540^{\circ} \mathrm{C}$ and this value decreased to $480^{\circ} \mathrm{C}$ for the film containing 6 at $\%$ cobalt.

(iii) Confirmation of cobalt heterogeneity in Co-modified films: Temperature dependence of coercivity of the Co-modified $\gamma-\mathrm{Fe}_{2} \mathrm{O}_{3}$ films grown by oxidation of Co-modified $\mathrm{Fe}_{3} \mathrm{O}_{4}$ films at different annealing temperatures $\left(250-450^{\circ} \mathrm{C}\right)$ were studied to find out the nature of anisotropy in the films introduced by $\mathrm{Co}^{2+}$ ions and the nature of cobalt dispersion in the $\gamma-\mathrm{Fe}_{2} \mathrm{O}_{3}$ matrix. Figure 21 shows the temperature dependence of $H_{\mathrm{c}}$ value of the films grown at oxidation temperatures $250,300,400$ and $500^{\circ} \mathrm{C}$. In the $H_{c}(T)$ plot (for $T \leqslant 200^{\circ} \mathrm{C}$ ) relatively low magnitude of the slope, which were $-1.8\left(T_{\mathrm{ox}}=250^{\circ} \mathrm{C}\right)$ and $-2.9\left(T_{\mathrm{ox}}=300^{\circ} \mathrm{C}\right)$ for the $\gamma-\mathrm{Fe}_{2} \mathrm{O}_{3}$ films grown at oxidation temperature $<350^{\circ} \mathrm{C}$, indicated that $H_{\mathrm{c}}$ of these films was independent of temperature. This indicated that uniaxial anisotropy which is not affected by temperature, as found in case of Co-absorbed media, was present in the film suggesting dispersed nature of cobalt. Higher magnitudes of the slope of $4.2\left(T_{\mathrm{ox}}=400^{\circ} \mathrm{C}\right)$ and $8.6\left(T_{\mathrm{ox}}=500^{\circ} \mathrm{C}\right)$ for the $\gamma-\mathrm{Fe}_{2} \mathrm{O}_{3}$ films oxidized at temperature $>350^{\circ} \mathrm{C}$ suggest that magnetocrystalline anisotropy (Nakamura et al 1987) which has a strong inverse dependence on temperature was present in the $\gamma-\mathrm{Fe}_{2} \mathrm{O}_{3}$ films grown at $T_{\mathrm{ox}}>350^{\circ} \mathrm{C}$, as shown in Co-doped films. Curie temperature study for the Co-modified $\gamma-\mathrm{Fe}_{2} \mathrm{O}_{3}$ films grown at oxidation temperature of $250^{\circ} \mathrm{C}$ and $400^{\circ} \mathrm{C}$ showed $T_{\mathrm{C}}$ values of $635^{\circ} \mathrm{C}$ and $405^{\circ} \mathrm{C}$ respectively.

\section{Growth mechanism}

\subsection{Cold-wall CVD reactor}

The gas-phase interactions of $\mathrm{Ar}, \mathrm{O}_{2}, \mathrm{Fe}(\mathrm{acac})_{3}$ vapours were inhibited due to the cold-wall design of the reactor. Fragmentation of (acac) $)_{3}$ ligand at substrate surface 
leads to $\mathrm{CH}_{3}^{+}$radical and secondary reactions leading to its further dissociation into $\mathrm{CO}, \mathrm{CO}_{2}$ and $\mathrm{H}_{2} \mathrm{O}$. This depletes oxygen in the vicinity of the substrate. Mass spectrometric data have shown that these secondary reactions and hence oxygen depletion are strongly influenced by temperature (Reichert et al 1970). Both the rate of formation of $\mathrm{CO}_{2}\left(\approx\right.$ rate of consumption of $\left.\mathrm{O}_{2}\right)$ and volume fraction of $\mathrm{CO}_{2}$ dramatically increase as the temperature increases from 485 to $515^{\circ} \mathrm{C}$ (Mellor 1946).

In the three-step scheme, deposition was done keeping substrate temperature in the range of $350-450^{\circ} \mathrm{C}$. In this temperature range, formation of $\alpha-\mathrm{Fe}_{2} \mathrm{O}_{3}$ phase was favoured owing to the relatively high oxygen supply near the substrate. As brought out from the microstructural studies, iron oxide films deposited in three-step scheme had a relatively lower density of nucleation centres. The growth of films occurred by a coalescence process resulting in the formation of larger grains and grain clusters. Such structural evolution was a consequence of high mobility of dissociated $\mathrm{Fe}^{2+} / \mathrm{Fe}^{3+}$ ions or $\mathrm{Fe}$ atoms on the substrate surface and possibly due to their lower rate of oxidation (oxygen supply was high enough to form as-deposited $\alpha-\mathrm{Fe}_{2} \mathrm{O}_{3}$ films but at the same time low enough to form oxygen-deficient phases in the as-deposited films) to form iron-rich iron oxide. At flat orientation of the substrate, inevitably a low $\mathrm{Fe}^{2+} / \mathrm{Fe}^{3+}$ flux density favours a smaller number of nucleation sites and large grains as was indeed observed. The coexistence of dispersed stoichiometric $\gamma-\mathrm{Fe}_{2} \mathrm{O}_{3}$ grains and $\mathrm{Fe}$-rich $\gamma-\mathrm{Fe}_{2} \mathrm{O}_{3}$ clusters caused inclusion of additional magnetic anisotropy in the film arising from microstructural variations. This anisotropy, referred to as the microstructure-induced anisotropy, was responsible for the observed high values of $H_{\mathrm{c}}$ and $M_{\mathrm{r}}$ parameters in the films. In terms of the mechanism of direct deposition of $\gamma-\mathrm{Fe}_{2} \mathrm{O}_{3}$, the presence of oxygen-deficient phases, confirmed by lattice parameter studies, was due to a controlled and slower oxidation kinetics. Since low deposition temperatures $\left(350-450^{\circ} \mathrm{C}\right)$ favour $\alpha-\mathrm{Fe}_{2} \mathrm{O}_{3}$ phase, it seems that at higher deposition temperatures, intake of oxygen during formation of iron oxide was somehow depleted. Consequently, formation of $\mathrm{Fe}_{3} \mathrm{O}_{4}$ and its in situ oxidation to $\gamma-\mathrm{Fe}_{2} \mathrm{O}_{3}$ became possible. Reactive growth of iron oxide films in this technique was entirely due to pyrolysis of $\mathrm{Fe}(\mathrm{acac})_{3}$ complex upon interaction with the glass substrates held at high temperature of $500^{\circ} \mathrm{C}$. A balance in the $\mathrm{CO}, \mathrm{CO}_{2}$ and $\mathrm{O}_{2}$ for a direct growth $\gamma-\mathrm{Fe}_{2} \mathrm{O}_{3}$ films is, therefore, possible under certain experimental conditions only.

\subsection{Hot-wall CVD reactor}

In terms of the mechanism, it appears that the direct deposition of $\mathrm{Fe}_{3} \mathrm{O}_{4}$, as confirmed by XRD analysis, was due to a controlled and slower oxidation kinetics. Reactive growth of iron oxide films in this technique is entirely due to pyrolysis of $\mathrm{Fe}(\mathrm{DPM})_{3}$ complex upon interaction primarily with the substrate held at high temperature and with the hot walls of the reactor. In principle, introduction of $\mathrm{O}_{2}$ would have led to growth of $\alpha-\mathrm{Fe}_{2} \mathrm{O}_{3}$ phase which is a higher oxidation state of iron oxide. Fragmentation of the DPM ligand at hot wall leads to its further dissociation into $\mathrm{CO}, \mathrm{CO}_{2}$ and hydrocarbon species (Reichert et al 1970). These vapours, particularly $\mathrm{CO}$ and $\mathrm{CO}_{2}$, on coming in contact with the heated substrate surface where iron radical formation was taking place, provided an environment favourable for the growth of iron oxide films in a lower oxidation state, viz. $\mathrm{Fe}_{3} \mathrm{O}_{4}$. Thus, a limited 
supply of $\mathrm{O}_{2}$ favoured formation of $\mathrm{Fe}_{3} \mathrm{O}_{4}$ phase thermodynamically. A direct deposition of $\mathrm{Fe}_{3} \mathrm{O}_{4}$ (magnetic) films therefore took place under certain experimental conditions only as described above.

As discussed earlier, $\gamma-\mathrm{Fe}_{2} \mathrm{O}_{3}$ phase was formed by the oxidation of $\mathrm{Fe}_{3} \mathrm{O}_{4}$ phase derived from the reduction of $\alpha-\mathrm{Fe}_{2} \mathrm{O}_{3}$ phase. By depositing $\mathrm{Fe}_{3} \mathrm{O}_{4}$ phase directly we are able to eliminate one process step in the way to form magnetically stable $\gamma-\mathrm{Fe}_{2} \mathrm{O}_{3}$ phase. In the LPCVD process described here, a direct formation of $\mathrm{Fe}_{3} \mathrm{O}_{4}$ phase is likely to be assisted by the controlled partial pressure of $\mathrm{O}_{2}$ and gas-phase reaction as promoted by hot-wall-type reactor chamber.

\section{Conclusions}

(i) In three-step scheme, high $M_{\mathrm{r}}, H_{\mathrm{c}}$ and SQ values of $270 \mathrm{mT}, 61 \mathrm{kA} / \mathrm{m}$ and 0.76 are observed in $\gamma-\mathrm{Fe}_{2} \mathrm{O}_{3}$ films. Microstructural anisotropy is introduced by the iron-rich clusters as promoted by cold-wall-type reactor chamber. As a result considerable enhancements in the magnetic properties of the film are realized.

(ii) In two-step scheme, we have demonstrated a technique based on the chemical phase dissociation of Fe-organic complex for a direct growth of $\mathrm{Fe}_{3} \mathrm{O}_{4}$ thin films. High coercivity of $122 \mathrm{kA} / \mathrm{m}$, remanence value of $102 \mathrm{mT}$ and SQ value of 0.80 of the $\gamma-\mathrm{Fe}_{2} \mathrm{O}_{3}$ films of thickness $\approx 800 \AA$ as obtained by oxidation of as-deposited $\mathrm{Fe}_{3} \mathrm{O}_{4}$ film are quite attractive for application in magnetic information recording. $\mathrm{A}$ two-step growth of $\gamma-\mathrm{Fe}_{2} \mathrm{O}_{3}$ films, achieved using a LPCVD technique described here, offers a considerable simplification of the process technology. The manifestation of the condition of the controlled oxidation kinetics required for the direct growth of $\mathrm{Fe}_{3} \mathrm{O}_{4}$ films is attributed to the secondary reactions during the pyrolysis of metal-organic compound.

(iii) In single-step scheme, we have demonstrated a technique based on chemical phase dissociation of Fe-organic complex for direct growth of $\gamma-\mathrm{Fe}_{2} \mathrm{O}_{3}$ thin films which offers a great simplification of process technology. Typically the high coercivity value of $237 \mathrm{kA} / \mathrm{m}, M_{\mathrm{r}}$ value of $280 \mathrm{mT}$, SQ and $S^{*}$ values of 0.83 and 0.60 of these films obtained by adding 6 at \% of cobalt make them most suitable for high-density magnetic information recording. Strong temperature dependence of coercivity indicated presence of magnetocrystalline anisotropy in the Co-doped $\gamma-\mathrm{Fe}_{2} \mathrm{O}_{3}$ films.

(iv) Biaxial magnetic studies, magnetic studies at temperature higher than the Curie temperature of $\gamma-\mathrm{Fe}_{2} \mathrm{O}_{3}$ and temperature dependence of coercivity have demonstrated a new dispersion mode of Co-incorporation in $\gamma-\mathrm{Fe}_{2} \mathrm{O}_{3}$ thin film which considerably enhances the magnetic properties in the films. High values of $M_{\mathrm{r}}$ of $220 \mathrm{mT}, H_{\mathrm{c}}$ of $65 \mathrm{kA} / \mathrm{m}$ and SQ of 0.60 should be of considerable interest for the application of these films as recording media.

\section{Ācknowledgements}

The investigation of direct growth of $\mathrm{Fe}_{3} \mathrm{O}_{4}$ film was carried out in close association with Drs N E Fedotova, N V Gelfond and A F Bykov of Institute of Inorganic Chemistry, Novosibirsk, Russia. We thank them for their suggestions and help in the preparation of precursors and design of the hot-wall-type LPCVD reactor used in this study. We thank transmission electron microscopy group in our laboratory 
for extending the TEM/SAED facilities. We also thank surface science group of our laboratory for measuring and analysing depth profile data. One of us (SD) also thanks R K Kotnala and B R Awasthy for their helpful discussion.

\section{References}

Abe M and Gomi M 1990 J. Magn. Magn. Mater. 84222

Babkin E V, Koval K P and Pynko V G 1984 Thin Solid Films 117217

Bate G 1965 IEEE Trans. Magn. 3193

Bate G 1978 IEEE Trans. Magn. 14136

Beck P A 1971 Metall. Trans. 21971

Chantrell R W and O'Grady K 1992 J. Phys. D. Appl. Phys. 251

Chen M M, Kakalec M A, Ju K, Tsang C and Castillo G 1988 IEEE Trans. Magn. 242988

Dhara S, Malhotra G L, Rastogi A C and Das B K 1992a Thin Solid Films 209116

Dhara S, Kotnala R K, Rastogi A C and Das B K 1992b Jpn. J. Appl. Phys. 313853

Hattori S, Ishii Y, Shinohara M and Nakagawa T 1979 IEEE Trans. Magn. 151549

Hayama F, Kitaoka S, Kishimoto M, Anodh H and Amemiya M 1980 Proc. Int. Conf. ICF 3521

Heller J 1976 IEEE Trans. Magn. 12396

Imaoka Y, Umeki S, Kubota Y and Tokuoka Y 1978 IEEE Trans. Magn. 14649

Inagaki N, Hattori S, Ishii Y, Terada A and Katsuraki H 1976 IEEE Trans, Magn. 12785

Iwasaki S, Nakamura $Y$ and Ouchi K 1979 IEEE Trans. Magn. 181456

Kishimoto M, Sueyoshi T, Hirate J, Amemiya M and Hayama F 1979 J. Appl. Phys. 50450

Koster E 1972 IEEE Trans. Magn. 8428

Kotnala R 1992 Bull. Mater. Sci. 15149

Lu P and Charap S H 1992 IEEE Trans. Magn. 28986

Mee J E, Archer J L, Meade H R and Hamilton T N 1967 Appl. Phys. Lett. 10289

Meiklejohn W H 1986 Proc. IEEE 741570

Mellor J W 1946 Inorganic and theoretical chemistry (London: Longmans, Green and Co.) V 816

Meng R L, Wang Y Q, Liu C S, Bensaoula A, Chu C W, Hor P H and Egnatiev A 1987 J. Appl. Phys. 613883

Nakamura H, Ohmi F, Kaneko Y, Sawada Y, Watada A and Machida H 1987 J. Appl. Phys. 613346

Ohta S and Terada A 1986 Thin Solid Films 14373

Ouchi K and Iwasaki S 1988 IEEE Trans. Magn. 243009

Reichert C, Bancroft G M and Westmore J B 1970 Canadian J. Chem. 481362

Slonczewski J C 1958 Phys. Rev. 1101341

Speliotis D E and Judge J P 1991 J. Appl. Phys. 695157

Tachiki M 1960 Prog. Theo. Phys. 231055 